In the end I managed to peg out a line, down as much of the axis as I could get at, $5^{2} 3$ feet long, from the columns in front of the sanctuary down to the lower end of the Hypostyle Hall; unfortunately, both the extremities of the line are blocked up. The sanctuary itself is completely filled up with the huge stones of the fallen roof, and the last columns of the Great Hall at the other end are at present built round with stones and bags of sand on account of the repairs being carried out to the neighbouring pylon, while the pylon itself is timbered up to prevent its falling, so that the two important points for a survey of this part of the axis cannot be used at present.

The line at this end of the axis had to be continued by the theodolite alone, as no measures for centring were possible, as it had to be carried through the Rameses Pylon into the Outer Court so far as the standing pillar of Tirhakah in order to get the true bearing of the central line by observations of the Pole Star, that star not being visible from any place on the axis inside the buildings.

The result of the survey in general quite confirms the data used by Sir Norman Lockyer in fixing the date at which the original axis was laid down, viz. about 3700 B.c. $\rightarrow$ a date which M. Legrain fully accepts on the results of his excavations, as the building of the upper end of the temple has been assigned on archæological grounds to about this period; indeed, two statues have been dug out by him, both now in the Cairo Museum, which give direct evidence as to the date. One is a seated figure of Cheops with his cartouche (of the fourth dynasty), the date of which is given in the lists as B.C. 3733 , and the other is a headless figure which has been assigned to the work of the third dynasty. These figures were, of course, dug up long after Sir Norman Lockyer's survey; no older work has been found.

The height of the hills behind which the sun used to set at the summer solstice, to which the temple was oriented, was taken at $2^{\circ} 30^{\prime}$. From the spot I was able to climb up to on the stones filling the sanctuary, to what I thought was about the height of an altar, I made it a little more; but as I had to see the hills through the timbering of the Rameses Pylon, between the struts, I could only measure the small part which was not covered if this is the correct height, as I believe it to be, it would make the date of the foundation a little earlier, possibly to the time of the headless statue, which $M$. Legrain has assigned to B.c. 4000 .

There are a great many difficulties just now in carrying out such an accurate survey as is required to arrive at an astronomical date of any value on account of great work that is being carried on. It nust be remembered that the temple is about 1200 feet long, and stands on an area about five times that of St. Paul's, and is divided into numerous halls, corridors, and gateways; but all these are connected by the axis which runs through the whole building from east to west. This axis, when originally laid down, pointed to the place on the hill at which the sun disappeared behind it on the longest day, and the difference between the place where the sun set then and where it sets now gives the date of the foundation of the temple, the rate of the sun's change in declination being known.

M. Legrain tells me that in about two years' time he will have cleared out the fallen roof of the sanctuary, and that by that time he hopes the repairs to the Rameses Pylon will be completed and the timbering removed. In that case a unique opportunity will present itself for a survey of the whole of the axis at once from the court behind the opened-out sanctuary right down to the Ptolemaic Pylon at the west; and this Mr. Dowson, the Director-General of the survev in Cairo, has very kindly undertaken to have done by the survey officers so soon as the work is completed.

20 Hyde Park Place, W., October Ir.

\section{A Possible Relation between Uranium and Actinium.}

IT is believed fairly generally that actinium has its source in the disintegration of uranium, although it is not a member of the direct line of descent through radium. This belief is based mainly on the fact that actinium and its products have a constant ratio to uranium in minerals, and since this ratio is very small actinium is supposed to be a branch-product.

In The Philosophical Magazine for September Mr. G. N. Antonoff describes some experiments in which a new product is obtained, called uranium $\mathrm{Y}$, and gives strong reasons for the view that it is derived, not from uranium $\mathrm{X}$ but directly from uranium. It is always in a small ratio to uranium X. Antonoff has shown that it is probably a branch-product, and a possible origin of the actinium series.

The following considerations may indicate how such a branch-product could be formed. They were not thought worthy of mention until the starting point of a branchseries had been found experimentally. If a single atom of uranium begins to disintegrate, it ordinarily leads to the whole radium series, without disturbance from other atoms. But the molecule of uranium will contain at least two atoms chemically combined, and perhaps a large number. An instability arising in one atom may frequently produce a similar instability in a contiguous atom, or even a projection of one atom into another, so that two atoms may break up together and form new combinations.

The scheduled atomic weight of uranium is 238.5 . Two such atoms have a weight 477 . If they break up together and form only one substance, it might have a molecular weight equal to that of uranium, or $\frac{1}{2}, \frac{1}{3}, \ldots$ of that of the combined atoms. On the assumption that three atoms of a substance are formed, its atomic or molecular weight is 159 .

The experiments of Russ appear to give the most trustworthy value of the atomic weight of actinium emanation. They showed that the thorium emanation is $I .42$ times as heavy as that of actinium. If thorium emits two a particles, both helium atoms, its emanation should have an atomic weight about 224. The atomic weight of actinium emanation thus becomes about ${ }_{5} 56$.

On a theory of the constitution of the elements given to the British Association by the writer at Portsmouth, it is more likely that the emanation from thorium has the same atomic weight as that from radium, and that actinium emanation has an atomic weight of $\mathbf{5}^{2} \cdot 5$. Russ's experiments would then lead to a value very close to this for actinium emanation. It is, of course, difficult in most cases to obtain satisfactory conclusions from such experiments on diffusion, but there are strong grounds for thinking that in this special case the usual sources of error have been minimised.

If uranium $\mathrm{Y}$ be formed in this way, with an atomic weight 159 , it may well be the parent of actinium, whether the suggested atomic weight of the emanation be correct or not and it is not unlikely that at certain stages in the radium series a similar series of branch-products of low atomic weight may be produced. There is evidence of this in the complex product radium $\mathbf{C}$.

Trinity College, Cambridge, October ir.

$$
\text { J. W. Nicholson. }
$$

\section{Hot Days in Igrx.}

Mr. MacDowall's letter in Nature of October I2 (p. 485 ), in which he directs attention to certain features in the sequence of annual number of hot days at Greenwich, is interesting. Nevertheless, I think he himself will acknowledge that his example, viz. the summer of I9II, is a happy one. What his diagram would lead one to expect if one were making a forecast, and not a retrospect, is that the number of hot days in I9II would lie between his lower limit of 90 days and an upper limit of about $90+130$, or 220 days; the value half-way between the two, i.e. 155 days, being the "most probable." Clearly in this case the upper limit, and also the most probable value, may be disregarded, and the lower limit is sufficiently high to be worthy of note.

The fact is that the dot for 1909, the ordinate of which is sought, lies on the lower edge of the boundary of the area of dots, so that in this case the lower limit gives a close approximation to the truth. If a dot happens to lie near the upper edge of the area of dots, the upper limit of its range along the vertical of the diagram becomes a close approximation. But since the difference between the upper and lower limits is no fewer than about Izo days,

NO. 2 IOO. VOL. 877 